\title{
Crude Tall-Oil: Uma Significativa Fonte em Ácidos Gordos e Resínicos
}

\author{
JOSÉ MANUEL F. NOGUEIRA *
}

Constituído por uma significativa variedade de ácidos gordos e resínicos, o crude Tall-Oil, recuperado como consequência da produção de celulose, pode ser superiormente analisado por cromatografia capilar gás-líquido e separado industrialmente por destilação fraccionada sob alto vácuo.

Uma retrospectiva relativa à obtenção, composição e aplicação deste sub-produto e a revisão dos principais métodos separativos ao nível analítico e industrial são contemplados na presente contribuição, assim como a caracterização e uma proposta alternativa de fraccionamento por extracção com solventes de amostras de crude Tall-Oil nacional.

\section{INTRODUÇÃO}

Portugal, país com grandes tradições florestais, possui uma flora conífera com predominância da espécie de pinheiro Pinus pinaster, vulgarmente conhecida por pinheiro bravo. Esta riqueza nacional movimenta fundamentalmente uma vasta indústria extractiva de colofónia e terebentina, provenientes da destilação sob arrastamento de vapor da gema do pinheiro, que faz ascender o nosso país ao topo dos internacionalmente mais cotados do sector. No entanto, nas tradicionais indústrias nacionais de celulose, a madeira das resinosas tem vindo ao longo dos anos a ser substituída pela madeira de eucalipto (Eucalyptus globulus) na produção de pasta de papel, encontrando-se esta última já largamente implantada em Portugal dada a sua reflorestação ser economicamente mais viável e, actualmente, somente a fábrica situada em Vila Velha de Rodão labora exclusivamente com madeira de pinho.

Na produção de celulose a partir do processo de Kraft (sulfato), recupera-se como maior sub-produto da manufacturação, o crude Tall-Oil (CTO), tendo este emergido no início

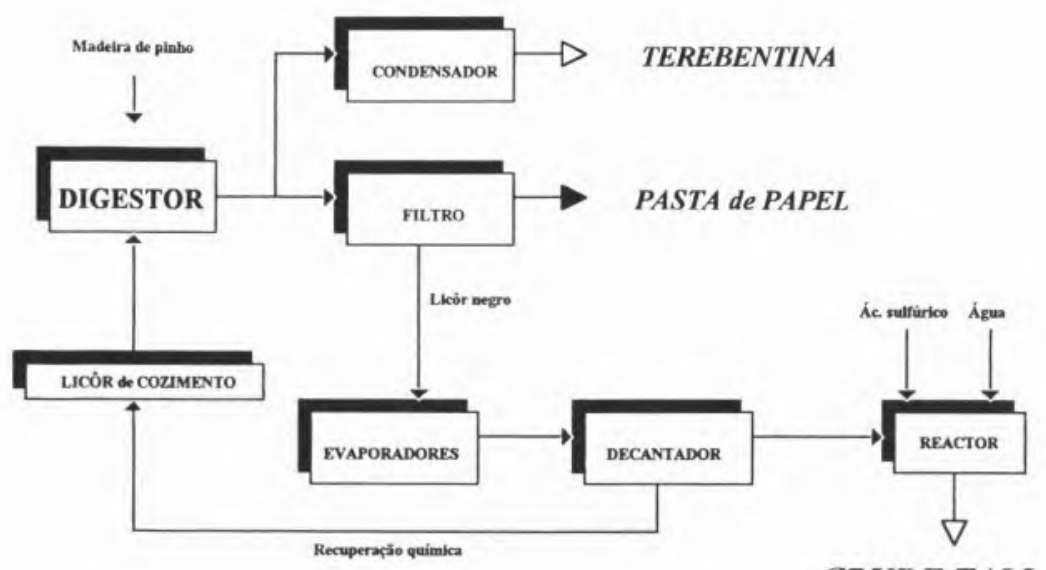

CRUDE TALL-OIL

Figura 1 - Diagrama de blocos referente à recuperação dos principais sub-produtos, provenientes do processo de Kraft, na produção da pasta de papel a partir da madeira de pinho.

do século XX na Escandinávia e só mais tarde em outros países, com o ressurgimento em força da indústria do Naval Stores [1]. Durante a digestão da madeira de pinho para obtenção da pasta, a lenhina é destruída pelo licor de cozimento fortemente alcalino $\left(\mathrm{NaOH} / \mathrm{Na}_{2} \mathrm{~S}\right)$, que conjugado com as altas pressões e temperaturas praticadas, liberta as fibras longas de celulose. Ao mesmo tempo, todos os glicerídeos existentes na resinosa são saponificados e os ácidos resínicos assim como os ácidos gordos formados são convertidos em sais de sódio, originando parte do licor negro designado por Tall-Oil soap, que após prévia decantação e acidificação dão origem ao CTO. Simultaneamente, o segundo maior sub-produto derivado da digestão da madeira, a terebentina, é recuperada do processo por condensação dum efluente gasoso. A designação escandinava originária, Tallolja, que significa óleo de pinho, foi mais tarde anglicizada para Tall-Oil, para a não confusão quanto à sua origem, do já consagrado Pine-Oil, extraído das raízes do pinheiro, caracterizando uma mistura heterogénea complexa, rica em variados tipos de componentes com diversas funcionalidades.

Os principais constituintes do CTO, subdividem-se em três importantes grupos ou classes distintas de compostos:
- ácidos gordos insaturados e saturados $(30-60 \%)$, com especial destaque para o oleico e linoleico, palmítico e esteárico, respectivamente;

- ácidos resínicos diterpénicos (40-60\%), de fórmula molecular $\mathrm{C}_{20} \mathrm{H}_{30} \mathrm{O}_{2}$, com especial relevo para as estruturas prevalecentes do abietano, pimarano e isopimarano, com funções ácidas donde se distinguem os ácidos abiético, desidroabiético, palústrico, neoabiético, pimárico, isopimárico e sandaracopimárico;

- Neutros ou insaponificáveis (7-10\%), essencialmente constituídos por hidrocarbonetos, ésteres e alcoóis com cadeia linear e diterpénica para além dos esteróides, sendo o mais comum o $\beta$-sitosterol.

Sob o ponto de vista biológico, estes constituintes estão localizados em diferentes zonas do pinheiro e apresentam funções diversas e bem distintas. Os ácidos gordos, têm origem nas reservas alimentares constituídas por glicerídeos localizados nas células parenquimatosas. Por seu turno, os ácidos resínicos, apresentam funções protectora e preservativa, relativamente a agressões do meio exterior e são produzidos pelas células do parênquima epitelial, situadas no canal ou ducto resinífero do lenho. De menor importância na composição do CTO, os neutros, são constituídos por diversos compostos resultantes do próprio metabolismo 
do pinheiro e também de produtos originados pela decomposição, pirólise e formação ocorridas durante a digestão da madeira.
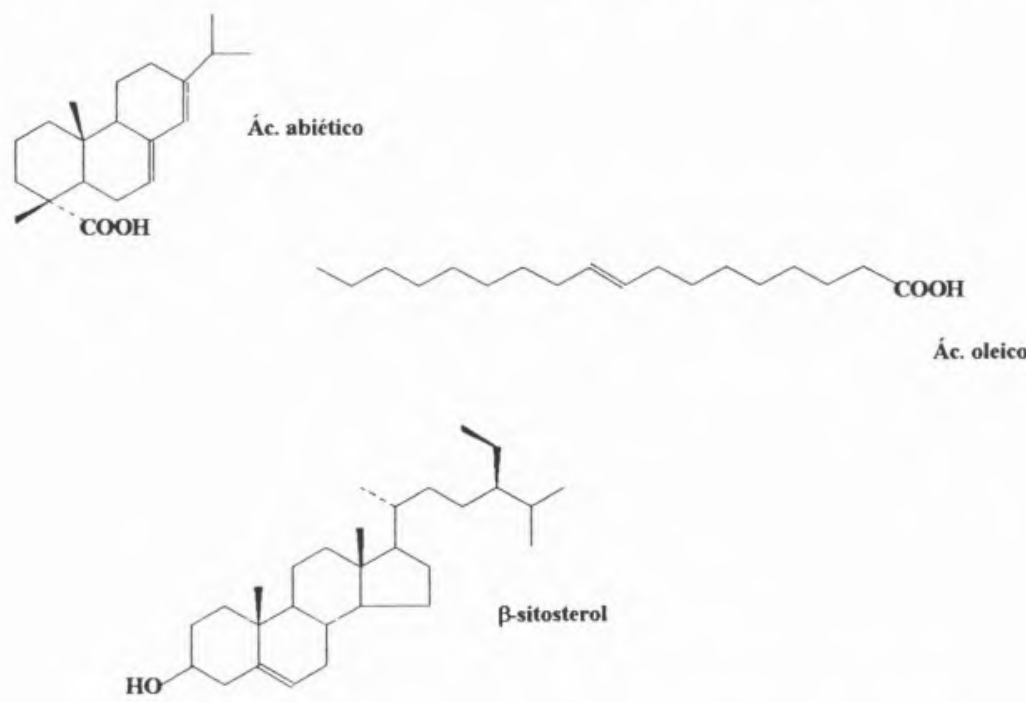

Figura 2 - Estrutura do principal componente da fraç̧ão gorda (oleico), resínica (abiético) e neutra ( $\beta$ sitosterol), existentes no CTO.

A composição química e a qualidade do CTO, variam significativamente com a localização geográfica, condições climáticas das florestas, espécies e respectiva idade dos pinheiros usados na produção de celulose. As alterações químicas, provocadas principalmente por oxidações, isomerizações, polimerizações e disproporcionações, que possam ocorrer durante o armazenamento, preparação, digestão da madeira e consequente recuperação do CTO, são importantes para possíveis variações composicionais. Do mesmo modo, a época do ano relativa ao corte dos pinheiros, influencia significativamente a composição, a qualidade e o rendimento recuperativo do crude, que em média não ultrapassa os $4 \%$, relativamente à pasta produzida.

Internacionalmente, a produção mundial de CTO ronda cerca de um milhão de toneladas por ano, tendo sido destilado em 1991 só na Europa, cerca de 443.000 ton [2], apresentando os produtos provenientes do fraccionamento importantes aplicações como matérias subsidiárias para di- versos tipos de indústrias, nomeadamente: tintas, vernizes, lacas, colas, adesivos, papel, resinas sintéticas, gomas, diversos tipos de revestimen-

Ac. oleico

to, lubrificantes, borrachas, agentes de flutuação, detergentes, sabões, desinfectantes, resinas para impressão tipográfica e de gravuras, indústrias têxtil, electrónica, alimentar, farmacêutica e até para asfalto [3].

Face à elevada aplicabilidade industrial dos componentes provenientes do fraccionamento do CTO, o vasto mercado de procura desenvolveu assim desde a década de quarenta, um crescente interesse em estudos de investigação e desenvolvimento nesta área, fundamentalmente com o início do primeiro fraccionamento para a obtenção de produtos destilados com elevado potencial de aplicação industrial e portanto possuíndo comercialmente maior valor acrescentado.

\section{MÉTODOS ANALÍTICOS DE SEPARAÇÃO}

Os mais recentes desenvolvimentos, relativos a técnicas separativas para o conhecimento composicional do CTO, centram-se essencialmente nos métodos cromatográficos, que fornecem elevada reprodutibilidade na análise das principais classes de compostos existentes, tendo-se fa- cilmente imposto face à rapidez, conveniência e exactidão demonstradas.

As modernas técnicas cromatográficas permitem isolar e identificar diversos componentes do CTO, como são os casos das cromatografias de camada fina (TLC), argentiométrica e em coluna (CC), demonstrando esta última técnica excelente aplicação na recuperação da fracção neutra do CTO, podendo ser superiormente separada da fracção acídica pelo método DEAE-Sephadex [4]. Com inúmeros contributos sobretudo como métodos preparativos, também se destacam as cromatografias líquidas na recuperação e análise de diversos tipos de compostos relativos à área do Naval Stores, como são o caso da cromatografia líquida de alta performance (HPLC) e da cromatografia de exclusão molecular ou permeação em gel (SEC), na separação de classes de compostos com estrutura semelhante ou de elevado peso molecular. No entanto, para separação dos principais componentes acídicos do CTO, somente se destaca com elevado sucesso a cromatografia de permeação em gel, tendo Chang [5], demonstrado elevada eficácia e conseguido obter excelente separação das fracções gorda, resínica e relativa aos dímeros existentes.

A cromatografia gás-líquido (GC), tem sido de longe a técnica analítica mais usada com maior número de contributos quer no campo da análise quantitativa, quer qualitativa, dada a alta eficiência de separação, fácil operacionalidade e elevada reprodutibilidade, sobretudo no que respeita aos principais compostos acídicos. Geralmente, a separação e identificação isoladas dos ácidos gordos e resínicos é feita por prévia derivatização para os correspondentes ésteres metílicos. A esterificação dos componentes acídicos das amostras de CTO, habitualmente efectuada com diazometano em meio éter dietilíco/metanol (9:1), é instantânea e quantitativa.

O uso de colunas de enchimento efectuados por diversos autores, foi naturalmente substituído pela introdução de colunas capilares de alta 
resolução (WCOT), constituídas por vidro ou sílica fundida, para análise cromatográfica dos ésteres metílicos dos ácidos resínicos existindo já uma vasta bibliografia, com múltiplos desenvolvimentos, sobretudo na tentativa de incrementar a eficiência, resolução e a selectividade dos principais compostos diterpénicos, encontrados em amostras resinosas. Duane Zinkel e o seu grupo tem sido o mais importante investigador no domínio do desenvolvimento e optimização ligada à análise, caracterização e separação por GC dos ésteres metílicos dos ácidos resínicos, evidenciando nas diversas publicações, como principal interesse, a total resolução dos compostos diterpénicos pelo uso de vários tipos de fases estacionárias com diversa polaridade. Este autor, promoveu como critério padrão para avaliação dos vários tipos de colunas e metodologias, a separação entre o par levopimarato/palustrato de metilo, difícil ou mesmo impossível de resolver em diversos tipos de colunas, demonstrando que colunas revestidas à base de succinato de butano-1,4-diol (BDS), se mostravam as mais eficientes na resolução dos ésteres metílicos diterpénicos, em tempo analítico aceitável. O State of the Art por ele publicado em 1986 [6], é um dos seus mais importantes contributos na análise GC de amostras contendo ácidos resínicos, com diversa origem.

Por seu turno, diversos autores demonstraram igualmente boa separação na análise por GC, dos ésteres metílicos de diversos tipos de ácidos gordos provenientes de amostras com origem animal e vegetal, usando vários tipos de colunas de enchimento e capilares de alta resolução. A identificação directa dos ésteres metílicos de ácidos gordos por GC, é dificultada por escassez de padrões adequados. Todavia, o recurso a colunas capilares com características mais polares, sobretudo à base de cianopropilo, provaram ser eficazes levando mesmo à identificação de isómeros geométricos em amostras complexas.
No caso da análise do CTO por GC, a junção da informação experimental adquirida isoladamente quer na separação dos ésteres metílicos dos ácidos gordos, quer dos resínicos, permite a melhor optimização para a obtenção conjunta da total separação e resolução da amostra. Nestler e Zinkel [7], foram os pioneiros na análise conjunta dos ésteres metílicos correspondentes aos ácidos gordos e resíni$\cos$, tendo usado colunas de enchimento com diversos tipos de fases es-

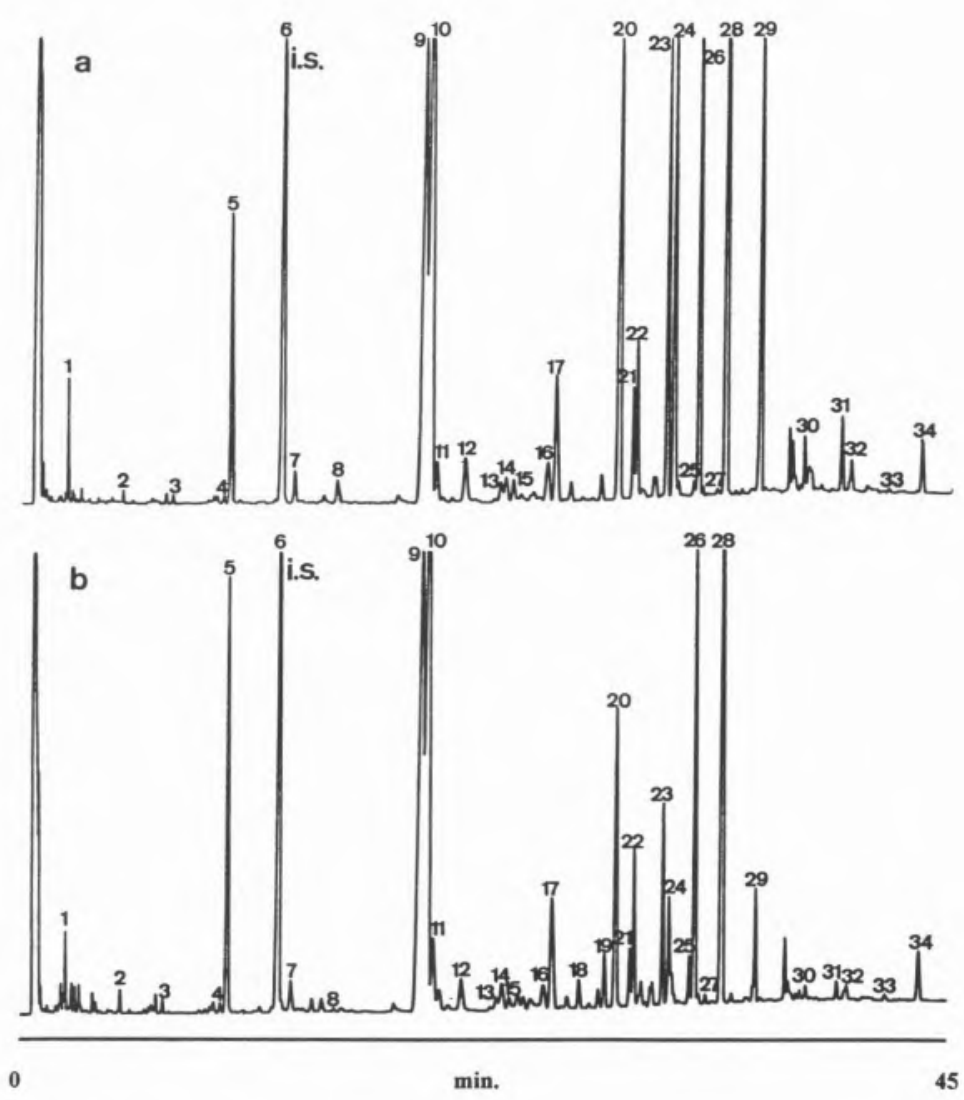

tacionárias e variada polaridade. Dorris et al. [8] e Holmbom [9], apresentam posteriormente importantes contributos na investigação operacional da separação dos ésteres metílicos dos ácidos resínicos e gordos provenientes da fracção acidíca de diversas amostras de CTO, aproveitando assim a elevada resolução demonstrada pelas colunas capilares, tendo ambos evidenciado cerca de 50 diferentes tipos de componentes, quer de ácidos gordos, quer de resínicos. Actual- mente, para separação simultânea dos ésteres metílicos dos ácidos gordos e resínicos do CTO, a cromatografia gasosa adopta essencialmente os dois géneros mais comuns de colunas capilares, com características de polaridade opostas, como são os casos das fases estacionárias apolares e polares à base de dimetilopolisiloxano $\mathrm{e}$ polietilenoglicol, respectivamente. A primeira constatação evidenciada relativamente ao uso de colunas polares, diz respeito à inversão na ordem 


\section{Espectrofotómetro Jasco Série-V UV/VIS}

\section{A escolha certa para as necessidades actuais}

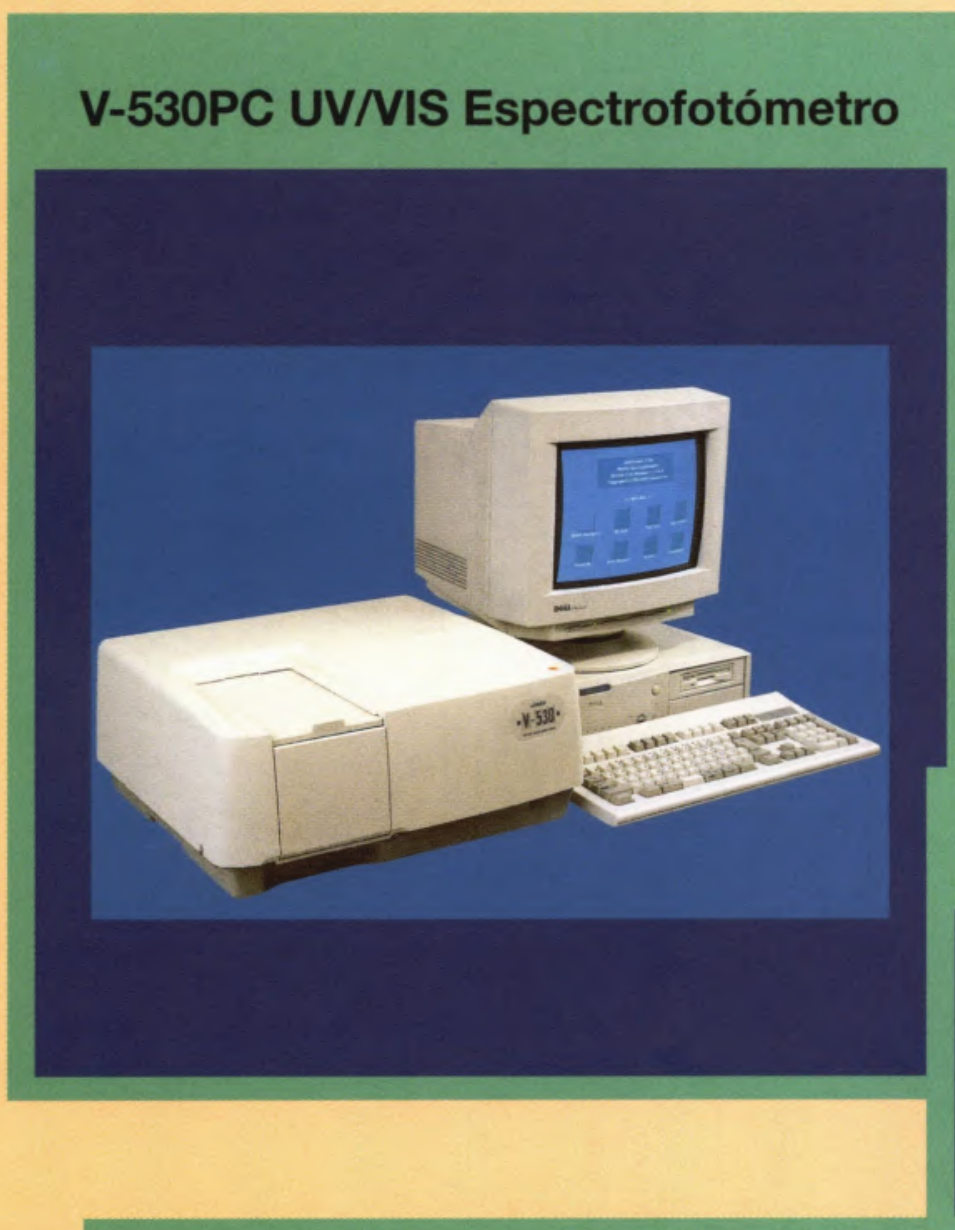

V-530iRM UV/VIS Espectrofotómetro

Especificações do Hardware

A melhor interface para o utilizador

- Duplo feixe

- Monocromador

- Gama de leitura 190 a 1100 nm

- Luz difusa menor que $0,04 \%$

- Largura de Fenda de 2 nm

\section{Características}

- Simples e de fácil utilização

- Design elegante e compacto

- Performances ópticas excelentes

- Gama versátil e completa de acessórios

- Software de validação (opcional) disponível

\section{A melhor interface para o utilizador}


de eluição obtida, quer por parte dos ésteres metílicos dos ácidos gordos quer dos resínicos, relativamente às colunas apolares, para além do tempo de análise ser superior, dada a maior interação das duplas ligações de diversos compostos com a fase estacionária polar.

As amostras de CTO após derivatização, são regra geral introduzi- das em injectores de vaporização $\left(\mathrm{T}_{\mathrm{inj}}>200^{\circ} \mathrm{C}\right)$ no modo de repartição de fluxo, optimizando-se um programa de temperatura ou usando-se condições isotérmicas ideais no

Tabela 1 - Principais componentes e composição química das duas amostras de crude Tall-Oil nacional (Rodão e Eixo), analisadas por cromatografia capilar gás-líquido, observados na Fig. 3.

\begin{tabular}{|c|c|c|c|c|c|}
\hline \multirow[b]{2}{*}{ Pico(a) $^{(a)}$} & \multirow[b]{2}{*}{ Nome sistemático } & \multirow[b]{2}{*}{ Nome comum } & \multirow[b]{2}{*}{ Abreviatura } & \multicolumn{2}{|c|}{$\% \mathbf{G C}^{(b)}$} \\
\hline & & & & Rodão & Eixo \\
\hline 1 & $\begin{array}{c}\text { 8-metileno-4,11,11-trimetilo-biciclo } \\
\text { [7.2.0] undeca-4-eno }\end{array}$ & $\beta$-cariofileno & $\longrightarrow$ & 0.51 & 0.35 \\
\hline 2 & ác.tetradecanóico & ác. mirístico & $14: 0$ & 0.07 & 0.14 \\
\hline 3 & ác. pentadecanóico & - & $15: 0$ & 0.07 & 0.10 \\
\hline 4 & ác. cis-9-hexadecenóico & ác. palmitoleico & $9-16: 1$ & 0.07 & 0.10 \\
\hline 5 & ác. hexadecanóico & ác. palmitíco & $16: 0$ & 2.55 & 4.25 \\
\hline 6 & Dibutilftalato & Padrão interno & i.s. & $\longrightarrow$ & $\longrightarrow$ \\
\hline 7 & ác. 14-metilohexadecanóico & $\longrightarrow$ & $17: 0$ ai & 0.35 & 0.38 \\
\hline 8 & ác. heptadecanóico & ác. margárico & $17: 0$ & 0.32 & traços \\
\hline 9 & ác. cis-9, cis-12-octadecadienóico & ác. linoleico & $9,12-18: 2$ & 9.44 & 12.77 \\
\hline 10 & ác. cis-9-octadecenóico & ác. oleico & $9-18: 1$ & 17.21 & 20.02 \\
\hline 11 & ác. trans-11-octadecenóico & ác. vacínico & $9 t-18: 1$ & 0.72 & 0.40 \\
\hline 12 & ác. octadecanóico & ác. esteárico & $18: 0$ & 0.79 & 0.45 \\
\hline 13 & ác. octadecanodienóico & $\longrightarrow$ & $?, ?-18: 2$ & 0.28 & 0.14 \\
\hline 14 & * * & $\longrightarrow$ & $?, ?-18: 2$ & 0.37 & 0.46 \\
\hline 15 & $\therefore$ & $\longrightarrow$ & $?, ?-18: 2$ & 0.28 & 0.17 \\
\hline 16 & " " & $\longrightarrow$ & $?, ?-18: 2$ & 0.68 & 0.43 \\
\hline 17 & " & $\longrightarrow$ & $?, ?-18: 2$ & 1.79 & 1.91 \\
\hline 18 & ác. 8,15-isopimaradieno-18-óico & $\longrightarrow$ & $\longrightarrow$ & $\longrightarrow$ & 0.36 \\
\hline 19 & ác. 8,15-pimaradieno-18-óico & $\longrightarrow$ & $\longrightarrow$ & $\longrightarrow$ & 0.63 \\
\hline 20 & ác. 8(14),15-pimaradieno-18-ico & ác. pimárico & $\mathrm{P}$ & 5.87 & 3.42 \\
\hline 21 & ác. 8(14),15-isopimaradieno-18-óico & ác. sandaracopimárico & $\mathrm{Sa}$ & 1.09 & 0.66 \\
\hline 22 & ác. cis-5, cis-11, cis-14-eicosatrienóico & - & $5,11,14-20: 3$ & 1.45 & 1.62 \\
\hline 23 & ác. 7,15-isopimaradieno-18-óico & ác. isopimárico & IP & 3.93 & 2.02 \\
\hline 24 & ác. 8,13-abietadieno-18-óico & ác. palústrico & Pal & 6.69 & 1.31 \\
\hline 25 & ác. 6,8,11,13-abietatetraeno-18-óico & ác. desidrodesidroabiético & DeDeAb & 0.12 & 0.45 \\
\hline 26 & ác. 8,11,13-abietatrieno-18-óico & ác. desidroabiético & $\mathrm{DeAb}$ & 10.08 & 4.78 \\
\hline 27 & ác. eicosanóico & ác. araquídico & $20: 0$ & 0.04 & 0.06 \\
\hline 28 & ác. 7,13-abietadieno-18-óico & ác. abiético & $A b$ & 21.42 & 21.11 \\
\hline 29 & ác. 8(14),13(15)-abietadieno-18-óico & ác. neoabiético & Neo & 7.74 & 0.93 \\
\hline 30 & ác. 7,13,15 abietatrieno-18-óico & $\longrightarrow$ & $\longrightarrow$ & 0.45 & 0.08 \\
\hline 31 & ác. 7-oxo-8,11,13-abietatrieno-18-óico & 7-oxodesidádroabiético & $\longrightarrow$ & 0.72 & 0.19 \\
\hline 32 & ác. docosanóico & ác. behénico & $22: 0$ & 0.37 & 0.14 \\
\hline 33 & ác. tricosanóico & ác. tricosóico & $23: 0$ & 0.12 & traços \\
\hline 34 & ác. tetracosanóico & ác. lignocérico & $24: 0$ & 0.58 & 0.67 \\
\hline
\end{tabular}

(a): ácidos como ésteres metílicos; (b): áreas normalizadas para 100\%, sem uso do factor de resposta ; Especifica-se para os ácidos gordos, A,B-N : $\mathbf{X}$, o comprimento da cadeia por $\mathbf{N}$, o número de duplas ligações por $\mathbf{X}$ e as respectivas posições na cadeia por $\mathbf{A}, \mathbf{B} \ldots ; \boldsymbol{c}$ e $\boldsymbol{t}$ significam cis e trans, que sem especificação a configuração é $\boldsymbol{c i s}$; $\boldsymbol{a}$ (anteiso) indica a existência de um metilo lateral na cadeia.; ?,? especifica desconhecimento posicional das duplas ligações. 
forno, tendo este procedimento extrema influência na resolução, dado os tempos de retenção dos compostos em causa apresentarem dependência térmica na eluição. A Fig. 3 reproduz a análise por GC efectuada a duas amostras de CTO nacional (Rodão e Eixo), apresentando boa separação e resolução nas condições usadas para além de tempo analítico aceitável (45min.), sendo os compostos identificados e sistematizados segundo a IUPAC apresentados na Tabela 1 .

A composição qualitativa diagnosticada, revela semelhanças com os compostos normalmente encontrados em amostras de CTO e DTO europeias e americanas, tendo os principais componentes acídicos sido identificados em ambas as amostras de CTO nacional por comparação dos tempos de retenção obtidos com padrões disponíveis e confirmados ulteriormente por GC-MS. Relativamente à fracção gorda destacam-se os ácidos oleico, linoleico e palmítico, e por parte da fraç̧ão resínica foram diagnosticados os ácidos abiético, desidroabiético, pimárico, isopimárico, palústrico, neoabiético e sandaracopimárico, para além de outros compostos diterpénicos vestigiais.

\section{SEPARAÇÃO E REFINAÇÃO INDUSTRIAL}

Com a descoberta em 1893, de que o licor negro resultante da digestão da madeira de pinho era constituído essencialmente por sais de sódio de ácidos gordos e resínicos, surge na Suécia em 1901 a primeira unidade de produção de CTO [12]. Este sub-produto da indústria da celulose, foi desde muito cedo sujeito a diversas tentativas de separação, tendo o primeiro passo sido dado nesse sentido também na Suécia em 1920, com a introdução de uma unidade de destilação simples, produzindo Tall-Oil destilado (DTO) com baixo grau de pureza e problemas de cristalização. A operação em batch inicialmente adoptada, foi mais tarde substituída pelo primeiro pro- cesso em contínuo patenteado em 1936, que já reclamava uma pureza de $70 \%$ para a fracção resínica e $94 \%$ para a gorda. Apesar da inovadora tecnologia introduzida, a subsequente cristalização não era resolvida, tendo esta questão somente sido solucionada na década seguinte pela introdução do processo de refinação ácida prévia à destilação, através do qual o CTO dissolvido em nafta era agitado com ácido sulfúrico concentrado $(88-100 \%)$, removendo-se conjuntamente a cor escura e os odores característicos. Só em 1949, na companhia "Arizona Chemicals", adoptando técnicas de destilação análogas às praticadas na indústria petrolífera de então, o fraccionamento dos ácidos gordos e resínicos começou a ser obtido com o elevado grau de pureza pretendido, tendo o processo sofrido significativos aprefeiçoamentos até aos nossos dias. A mais recente técnica de destilação, foi introduzida na Aústria em 1970 com tecnologia suiça (LuwaKrems System) e apresenta como principais novidades, torres de fraccionamento empacotadas, evaporadores de camada fina, diversos permutadores de calor e alto vácuo, tendo o know-how sido comercializado para diversas companhias destiladoras de CTO de todo o mundo. Os mais novos desenvolvimentos apresentam fundamentalmente a introdução de uma nova coluna de destilação (Super Rosin Column), mostrando este aperfeiçoamento maior preocupação por parte dos industriais, na obtenção de ácidos resínicos com a elevadíssima pureza pretendida no mercado internacional.

Actualmente, obtêm-se por destilação do CTO, cinco fracções (TOH, TOFA, DTO, TOR e TOP) de superior valor comercial, apresentando habitualmente este processamento perdas que rondam em média os $4 \%$, relativamente ao total do crude fraccionado. A diferença composicional destas cinco fraç̧ões, reside no grau de pureza que um conjunto típico de compostos com características químicas análogas, pode ter relativamente a outro com especial evidência para os ácidos gordos e resínicos, estando este grau de exigência condicionado quer ao processo tecnológico de fraccionamento e à origem do CTO usados, quer igualmente ao tipo de procura efectuada no mercado internacional, no que diz respeito à pureza pretendida.

Na separação do crude, destacam-se em primeiro lugar as cabeças $(\mathrm{TOH})$, constituídas pelos insaponificáveis leves e ácido palmítico, podendo este atingir em média $40 \%$ do total da fracção. Os ácidos gordos destilados (TOFA), essencialmente ácido oleico e linoleico, possuem uma contaminação em ácidos resínicos em média inferior a $3 \%$. Caso esta percentagem aumente e ultrapasse o referido valor, passamos a ter uma outra fracção conhecida por Tall-Oil destilado (DTO), na qual a percentagem em ácidos gordos é inferior a $90 \%$, relativamente aos diterpénicos. A fracção que contém os ácidos resínicos destilados (TOR), possui uma contaminação em ácidos gordos em média inferior a $4 \%$ e apresenta geralmente, diversas composições isoméricas dos próprios ácidos resínicos. O resíduo final (TOP), essencialmente constituído pelos insaponificáveis pesados como são os casos do $\beta$-sitosterol, dímeros e anidridos formados, para além de outros produtos originados pelo craqueamento e condensação de alguns constituintes durante o processo de fraccionamento, é substancialmente influenciado pelo tipo de equipamento e materiais usados na operação.

Apesar da eficácia separativa obtida pela destilação fraccionada, os dispendiosos gastos energéticos que envolvem estes processos, bem como as perdas significativas de materiais destilados com elevado peso molecular, com consequente formação de pitch, conduziram desde muito cedo a estudos de separação alternativos. Desde a década de quarenta, que diferentes métodos de separação têm sido desenvolvidos e testados com especial incidência para o estudo de processos que aproveitem as mais significativas diferenças nas proprie- 
dades fisíco-químicas dos ácidos gordos e resínicos existentes no CTO. Dentro dos métodos estudados, destacam-se como mais relevantes:

- A sulfonação selectiva dos ácidos gordos para os correspondentes ésteres do ácido sulfúrico, solúveis em meio aquoso [13];

- O tratamento térmico dos ácidos gordos e resínicos, produzindo separação pelas diferenças de difusão ocorridas com o gradiente de temperatura [14];

- A separação por formação selectiva de aductos cristalinos de ureia com ácidos gordos [15];

- A separação dos ácidos esteárico e abiético, por adsorção selectiva após prévia hidrogenação [16];

- A extracção selectiva dos ácidos gordos pela aplicação de propano sob pressão, conhecido por Solexol Process [17, 18];

- A extracção selectiva dos ácidos gordos e resínicos, pela diferença de afinidade existente para diversos solventes orgânicos imiscíveis, possuíndo diferente polaridade $[19,20]$;

- A esterificação selectiva dos ácidos gordos com diversos alcoóis, com posterior separação das fraç̧ões acídicas por extracção com solventes orgânicos imiscíveis, possuíndo dife- rente polaridade $[21,22]$.

No entanto, e apesar de inúmeros esforços, na indústria o processo de destilação fraccionada não sofreu substituição por outra tecnologia, dado os elevados investimentos requeridos para as alternativas propostas não justificarem as selectividades obtidas, aquando da separação da fracção gorda e resínica do CTO, já que a complexidade composicional deste sub-produto é bastante elevada. Nos mais recentes anos, têm surgido estudos muito interessantes no domínio da separação dos constituíntes do CTO, como é o caso do estudo piloto efectuado por Gembicki et al. [23] em 1983, demonstrando que através de adsorção selectiva em contínuo utilizando redes moleculares, era possível separar DTO e TOFA, tendo o autor obtido índices de pureza para as fracções gorda e resínica de $95 \%$ e para os ácidos oleico e linoleico de $92 \%$, respectivamente. Também os estudos efectuados por Briones et al. [24], na extracção de ácidos gordos de óleos naturais com água a elevadas pressões e temperaturas, demonstraram possibilidade na separação selectiva entre os ácidos gordos e resínicos do CTO, propondo o autor um esquema pro- cessual alternativo de extracção em contínuo.

A necessidade de retirar a elevadíssima percentagem de matéria insaponificável, verificada sobretudo no CTO escandinavo, como consequência do progressivo aumento de madeira não resinosa na produção de celulose, levou igualmente à investigação e desenvolvimento de diversas técnicas para extracção dos neutros, apresentando este procedimento prática industrial nos dias de hoje [25]. Com o intuíto de aperfeiçoamento do processo, em 1986 , Oksanen [26] desenvolveu no Technical Research Centre of Finland, um estudo piloto conhecido por Crude Soap Refining Process, tendo usado em contínuo extractores mixer-settler e colunas, conseguindo remover praticamente toda a fracção neutra e aumentar a qualidade do CTO, por consequente incremento do número de acidez. Em 1987 na Finlândia, Harvala et al. [27], estudaram igualmente à escala piloto a ex-

Figura 5 - Diagrama de blocos relativo às composiçōes médias (mM) dos ácidos gordos (HG) e resínicos (HR), obtidos no processo de extracção contínua em contra-corrente da amostra de CTO de Rodão com n-heptano.

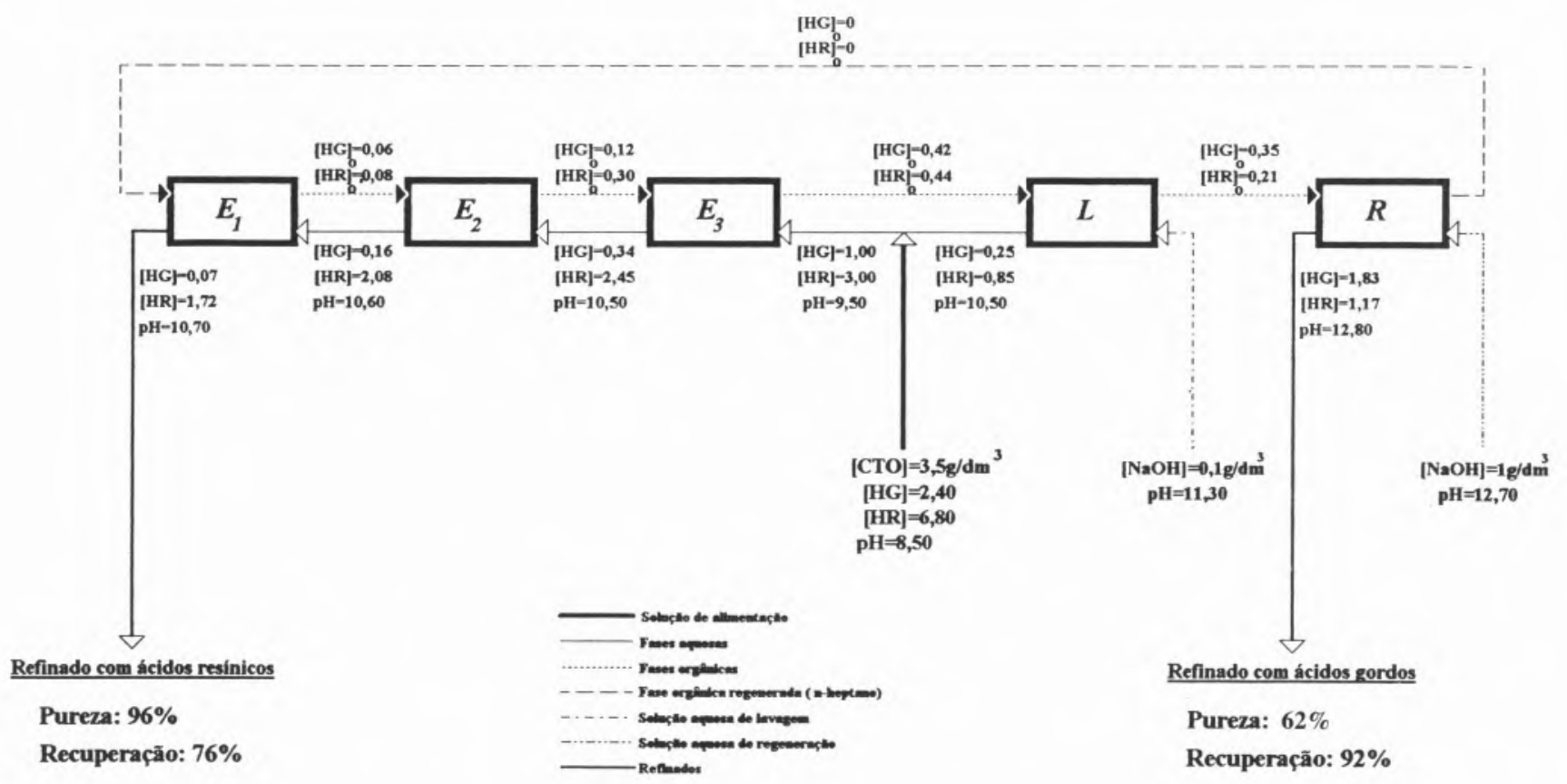



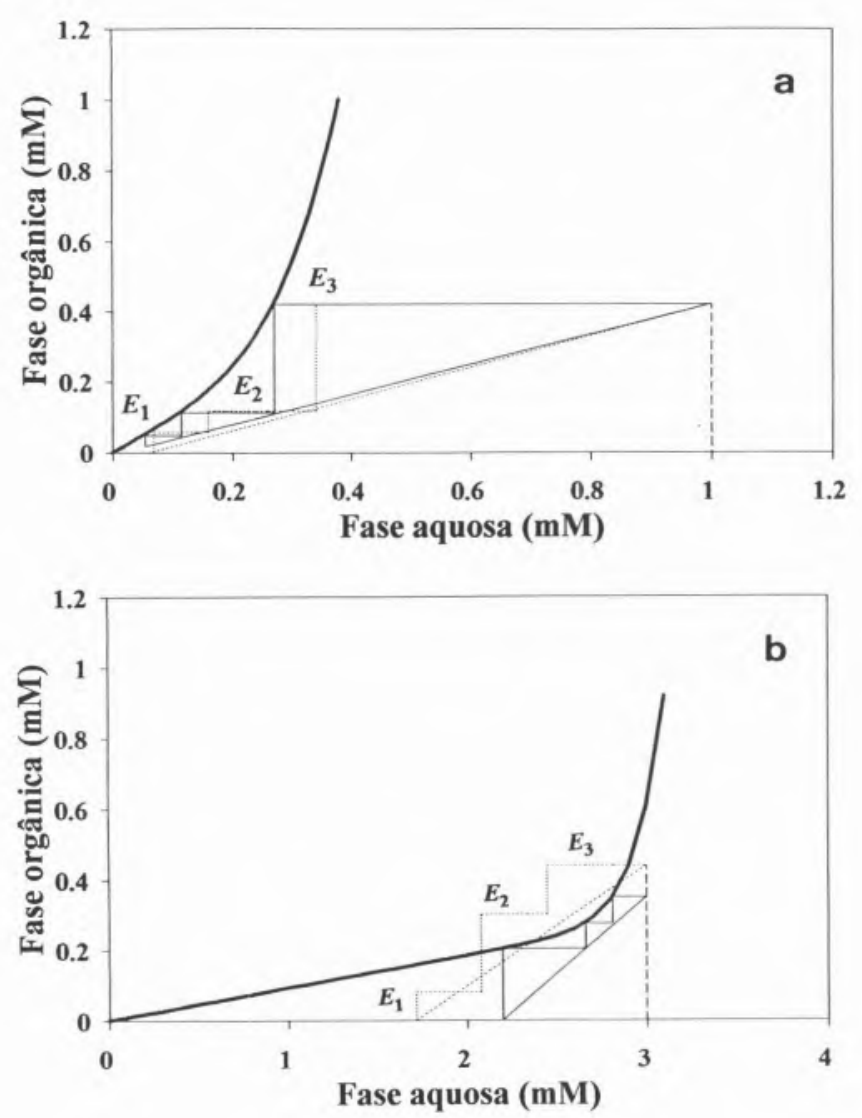

- Previsto Obtido

Figura 6 - Comparação das composições médias da fraç̧ão gorda (a) e resínica (b) da amostra de CTO de Rodão, obtidas na fase de extraç̧ão contínua em contracorrente com n-heptano do processo com um andar de lavagem, com as previstas pelo método gráfico de McCabe-Thiele para três andares de extração; (Temp.ambiente $\left(20^{\circ} \mathrm{C}\right) ; \mathrm{pH}=9,50$; [HG] 1,00mM, [HR] $=3,00 \mathrm{mM} ; 1<0,005 \mathrm{M} ; \mathrm{O} / \mathrm{A}=7 / 3$ ).

tracção supercrítica com dióxido de carbono, da fracção neutra do CTO, tendo obtido significativa selectividade relativamente à fracção acídica, somente quando o processo se efectua em estágios múltiplos, não constatando no entanto vantagens para separação entre a fraç̧ão gorda e resínica.

Para além dos processos referidos, nos últimos anos não têm surgido outras vias alternativas ou estudos à escala piloto no sentido de fraccionar o CTO, devido essencialmente ao obrigatório e inevitável dispendioso investimento não justificar o fim de refinar matéria prima de tão baixo valor comercial, embora existam outros factores que também pesem consideravelmente, nomeadamente a actual recessão internacional existente no sector das celuloses, o consequente aumento das recicladoras de papel, o incremento progressivo de outras espécies de árvores na produção da pasta de papel, sem esquecer o ressurgimento das fontes naturais para obtenção de ácidos gordos e resínicos, com origem em países de mão de obra intensiva e pouco onerosa, como é o caso da República Popular da China.

A produção nacional de CTO é baixa e da ordem das 2.600ton/ano, não justificando por isso mesmo o investimento de uma unidade de fracionamento por destilação, que actualmente só é economicamente recomendada para produções anuais iguais ou superiores a 100.000 ton. Os produtores nacionais sem capacidade que justifique, procedem à respectiva queima, aproveitando o seu poder calorífico na ordem das $35.000-40.000 \mathrm{~kJ} /$ ton. Assim, na tentativa de estudar uma alternativa viável no sentido da separação da fracção gorda da resínica à dimensão da produção de CTO nacional, foi testada a operação unitária de extracção com solventes orgânicos, tendo sempre em atenção o baixo valor que envolvem este tipo de materiais. Ensaios extractivos em contínuo, de soluções aquosas de sais de sódio contendo CTO a pH controlado, extraç̧ão por dissociação [28], em contra-corrente com solventes orgânicos, foram recentemente realizados tendo sido obtidos excelentes indíces de separação [29]. A Fig. 5 reproduz o diagrama de blocos adoptado.

Foram adoptados misturadores/decantadores (mixer-settler) à escala laboratorial, tendo sido usados 3 andares de extracção $\left(E_{1}, E_{2}\right.$ e $\left.E_{3}\right)$, um de lavagem $(L)$ e um de reextracção $(R)$, em concordância com o cálculo prévio por aplicação do método gráfico de McCabe-Thiele às curvas de distribuição isotérmicas linearizados. A Fig. 6 evidencia a comparação entre a evolução média composicional da fracção gorda e resínica da amostra de CTO de Rodão, na fase de extracção contínua em contra-corrente.

Este processo garantiu refinados contendo ácidos resínicos $\mathrm{e}$ gordos com purezas elevadas possuíndo $96 \%$ e $62 \%$ respectivamente, apresentando por isso mesmo alternativa credível e viável na separação dos principais componentes acídicos, fundamentalmente no isolamento dos ácidos resínicos. Este processo, sugere assim uma importância acrescida no mercado internacional, na crescente dificuldade em utilizar recursos humanos para a árdua tarefa da resinagem, tendo sido causa da sucessiva depleção da produção nacional de gema do pinheiro.

Apesar da crise mundial que paira de momento no sector das celuloses, sobretudo com o aparecimento das recicladoras de papel, seria de prever que o uso de madeira resinosa por parte dos produtores nacionais de celulose fosse aumentar necessariamente a produção nacional de CTO e ter consequências benéficas não só na qualidade da pasta produzida, bem como no interesse que os produtos posteriores ao seu fraccionamento poderiam oferecer à indústria portuguesa em geral. Os altos custos económicos que tal substituição poderia ocasionar, seriam 
provavelmente compensados igualmente em termos futuros pela diminuição do impacto ambiental que este tipo de indústrias provoca, sobretudo no que diz respeito à tradicional flora nacional, numa altura em que o peso do ambiente influencia cada vez mais as sociedades mundiais.

\section{Agradecimentos:}

O autor pretende agradecer à PORTUCEL S.A. as amostras de crude Tall-Oil cedidas, ao INETI as instalações para estudo em contínuo e à JNICT (Programa Ciência) o financiamento da bolsa de doutoramento.

Departamento de Química da Faculdade de Ciências da Universidade de Lisboa Campo Grande Ed. C1, 1700 Lisboa A presente contribuição é referente às provas de doutoramento intitulada "Separação dos Componentes do Crude Tall-Oil".

\section{BIBLIOGRAFIA:}

1. Zinkel, D.F., Russell, J., Naval Stores, Pulp Chemicals Association, New York, 1989.

2. Lofthouse, R., Proceedings of International Naval Stores Meeting, Pulp Chemicals Association, Viena de Austria, 1992

3. McSweeney, E.E., Arlt, H.G., Russell, J., Tall-Oil and Its Uses-II, Pulp Chemicals Association. Inc., Atlanta-GA, 1987.

4. Zinkel, D.F., Roew, I.W., Anal.Chem. 36 (1964) 1160.

5. Chang, T.L., Anal.Chem. 40 (1968) 989.

6. Zinkel, D.F., Han, J.S., Naval Stores Rev. 96 (1986) 14 .

7. Nestler, F.H.M., Zinkel, D., Anal. Chem. 39 (1967) 1118

8. Dorris, G.M., Douek, M., Allen, L.H., J. Am. Oil Chem. Soc. 59 (1982) 494.

9. Holmbom, B., J. Am. Oil Chem Soc. 54 (1977) 289 10. Nogueira, J.M.F., Pereira, J.L.C., Sandra, P. Proceedings of $16^{\text {th }}$ International Symposium on Capillary Chromatography, Hüting, Riva del Garda, Italy, 2 (1994) 1026.

11. Nogueira, J.M.F., Pereira, J.L.C., Fresenius J. Anal. Chem. 350 (1994) 379.

12. Drew, J.,Propst, M., Tall-Oil, Pulp Chemicals Association, New York, 1981

13. Vilbrandt, F.C., Chapman, P.E., Crockin, J.M. Ind. Eng. Chem. 33 (1941) 197.
14. Jones, A.L., Foreman, R.W., Ind. Eng. Chem. 44 (1952) 2249.

15. Moreno, J.M.M., Roncero, A.V., Valle, C., J. Anal. Fis. Quim. 47 (1953) 639.

16. Papps, G., Othmer, D.F., Ind. Eng. Chem. 36 (1944) 430 .

17. Passino, H.J., Ind. Eng. Chem. 41 (1949) 280

18. Zilch, K.T., J. Am. Oil Chem. Soc. 56 (1979) 739A.

19. Groyer, S.W., Ind. Eng. Chem. 40 (1948) 228.

20. Berg, R.L.V., Wiegandt, H.F., Chem. Eng. 6 (1952) 189.

21. Mueller, E.R., Eness, P.L., McSweeney, E.E., Ind. Eng. Chem. 42 (1950) 1532.

22. Dunlap, L.H., Hassel, L.V., Maxwell, J.L., J. Am. Oil Chem. Soc. 27 (1950) 361.

23. Gembicki, S.A., Shah, S.M., Cleary, M.T., Naval Stores Rev. 93 (1983) 9.

24. Briones, J.A., Mullins, J.C. Thies, M.C. I. Am. Oil Chem. Soc. 67 (1990) 852.

25. Ukkonen, K., J. Am. Oil Chem. Soc. 56 (1979) 897. 26. Oksanen, H., Naval Stores Rev. 96 (1986) 14. 27. Harvala, T., Alkio, M., Komppa, V., Chem. Eng. Res. Des. 65 (1987) 386.

28. Hanson, C., Recent Advances in Liquid-Liquid Extraction, Pergamon Press, Hungary, 1971.

29. Nogueira, J.M.F., Pereira, J.L.C., Proceedings do $14^{\circ}$ Encontro da Sociedade Portuguesa de Química, Univ. Aveiro, adenda (1994).

\section{SISTEMA DE ELECTROFORESE CAPILAR DA "HEWLETT-PACKARD"}

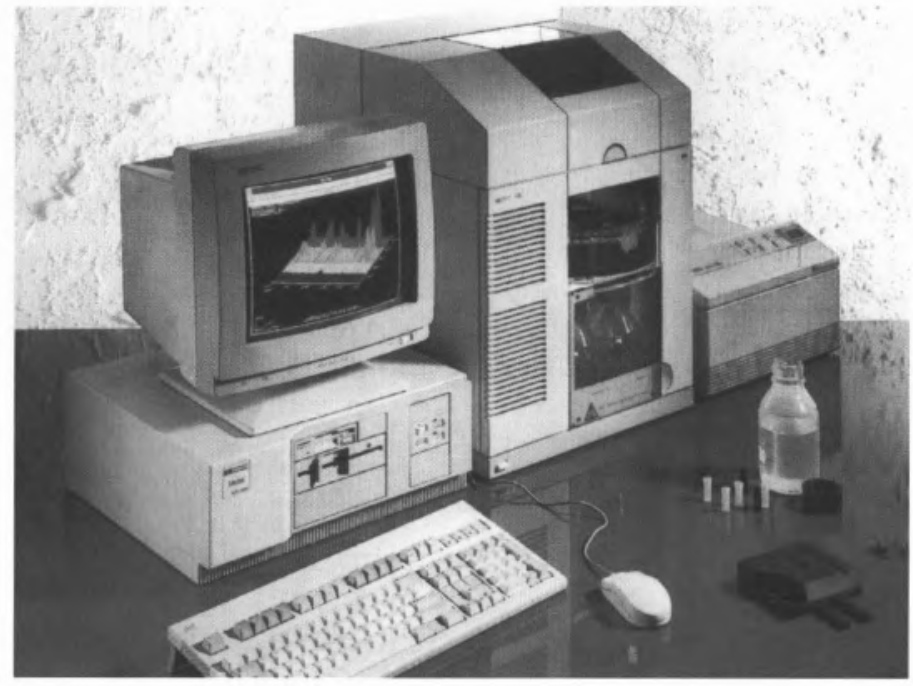

Detector DAD de alta sensibilidade

Possibilidade de uso de capilar de borbulha

\section{Software Tri-Dimensional}

Mudança automática de polaridade

\section{Carrocel com 48 posições}

